\title{
Graded refraction index antireflection coatings based on silicon and titanium oxides
}

\author{
Abdelhakim Mahdjoub \\ Laboratoire des Matériaux et Structures des Systèmes Electromécaniques et leur Fiabilité (LMSSEF) Centre \\ universitaire L. Benmhidi BP 358, 04000 O.E.Bouaghi Algeria \\ e-mail:abdelmah@yahoo.com
}

\begin{abstract}
Thin films with a graded refraction index constituted from silicon and titanium oxides were deposited by plasma enhanced chemical vapor deposition using electron cyclotron resonance. A plasma of oxygen reacted with two precursors: the tetraethoxysilane (TEOS) and the titanium isopropoxide (TIPT). The automatic regulation of the precursor flows makes it possible to modify the chemical composition, and consequently the optical index, through the deposited films. To control the thickness, the refraction index and the growth kinetics, in situ spectroscopic ellipsometer was adapted to the reactor. The analysis of ex situ ellipsometric spectra measured at the end of each deposition allow to determine a refraction index profile and optical properties of the inhomogeneous deposited films. Measurements of reflectivity carried out in the ultraviolet-visible-near infrared range show that these films could be used as antireflective coatings for silicon solar cells: $3.7 \%$ weighted average reflectivity between 300 and $1100 \mathrm{~nm}$ and $48 \%$ improvement of the photo-generated current were obtained.
\end{abstract}

Keywords: ellipsometry, graded index, AR coating.

Manuscript received 23.11.06; accepted for publication 26.03.07; published online 01.06.07.

\section{Introduction}

The quality of the anti-reflecting (AR) coatings is an essential criterion for the realization of highperformance solar cells [1]. To reduce the reflection, the surface of the solar cell is texturized before depositing the AR coating, mainly in silicon technology [2]. These modern coatings with hydrogenated silicon nitrides $(\mathrm{SiN}: \mathrm{H})$ are very appreciated because of their passivation properties [3-4]. For more powerful double layer antireflection (DLAR) coatings, common materials that were used for non-encapsulated solar cells include titanium dioxide $\mathrm{TiO}_{2}$ and silica $\mathrm{SiO}_{2}$ [5-6]. Another method of reducing the reflectivity consists in depositing an inhomogenous dielectric film presenting a gradually decreasing refraction index from the substrate towards the ambient [7-9]. These AR coatings, realizable in one technological stage, eliminate problems of interfaces between adjacent dielectric layers (constraints, bad adhesion, rough interface). Therefore, it is necessary to optimize the refraction index grading profile to get minimum reflectance. To realize these coatings, several materials (oxynitrites, hydrogenated nitrides, porous titanium oxide) deposited by using various processes (PECVD, sputtering techniques) were described in the literature [9-12]. Among the methods of deposition used, the plasma enhanced chemical vapor deposition using the electron cyclotron resonance (ECR-PECVD) allows to obtain materials with good dielectric properties deposited at low pressures and practically at the room temperature $[5,11]$.

In this work, proposed is a new profile for graded AR coating, using silicon and titanium oxides mixtures, which could replace the powerful classical DLAR coating $\mathrm{TiO}_{2} / \mathrm{SiO}_{2}$ [5-6]. For such applications, the control of the thickness and refraction index during deposition process is particularly valuable. In this work, in situ monochromatic ellipsometry was used for such measurements. In addition, the films deposited were characterized (ex situ) by spectroscopic ellipsometry and their performances evaluated by measurements of the spectral reflectivity.

\section{Experimental details}

The simplest method to obtain oxides by PECVD is to use $\mathrm{O}_{2}$ plasma. To obtain titanium or silicon oxides, two precursors were used: tetraethoxysilane (TEOS) and the titanium isopropoxide (TIPT). These precursors have several advantages: they are very easy to use, they are 
non-dangerous products (as compared to $\mathrm{SiH}_{4}$ ) and they are very volatile at low temperature (between the room temperature and $50{ }^{\circ} \mathrm{C}$ ). Moreover, the obtained films possess a weak carbon contamination [5].

The plasma was excited at the microwave frequency $(2.45 \mathrm{GHz})$ under electron cyclotron resonance (ECR) conditions. A nitrogen flow saturated with TIPT vapor allows the transport of this precursor to the oxidation chamber. The vapor of TEOS has a second access to the reactor. To avoid recondensation of precursors in the feed lines, they are heated to $50{ }^{\circ} \mathrm{C}$. The gas flows (TEOS, TIPT and $\mathrm{O}_{2}$ ) were controlled by automat. A Baratron gauge allows to measure the pressure during the deposition process which is usually about $1 \mathrm{mTorr}$. The temperature of the samples can be regulated between the room temperature and $400{ }^{\circ} \mathrm{C}$. All the depositions were made on single crystal $\mathrm{Si}(100)$ substrates. No sample polarization was applied.

The reactor chamber was equipped with a spectroscopic ellipsometer with rotating polarizer system. Incident angle is fixed at $70^{\circ}$. The classical ellipsometric method for in situ control consists of following the trajectory of the ellipsometric angles measured during the process $[5,12]$.

The two ellipsometric angles are defined by

$\rho=\left(\frac{R_{p}}{R_{S}}\right)=\operatorname{tg}(\psi) \exp (i \Delta)$,

where $R_{p}$ and $R_{s}$ are the Fresnel reflection coefficients.

Measurements were performed at the constant wavelength, chosen in the range where the deposited materials are transparent $(500 \mathrm{~nm}$ in our case). The $\Delta$ versus $\psi$ curves were plotted during the deposition in the Cartesian coordinates and compared to iso-index abacuses where the thickness constitutes the variable for a transparent film on silicon substrate [13].

After depositing, the ellipsometric spectra were systematically taken in various points of the sample to ensure the homogeneity of the deposited films.

The exploitation of ellipsometric measurements (in situ and ex situ) requires the use of models based on the stratified medium theory [13-15]. The calculated and measured spectra were compared to minimize an error function that generally expressed by

$$
\begin{aligned}
& \chi=\frac{1}{2 M} \sum^{M}\left[\operatorname{tg}\left(\psi_{\text {exp }}\right)-\operatorname{tg}\left(\psi_{\text {th }}\right)\right]^{2}+ \\
& +\left[\cos \left(\Delta_{\text {exp }}\right)-\cos \left(\Delta_{\text {th }}\right)\right]^{2} .
\end{aligned}
$$

The adjustment of the theoretical curves to the experimental spectra permits to determine the optical parameters of the deposited layer, namely, its thickness and the refraction index profile.

Optical indices of deposited materials $\left(\mathrm{SiO}_{2}, \mathrm{TiO}_{2}\right)$ were obtained from spectroscopic ellipsometry measurements. For Si substrate, we use the indices published by Palik [16].
To evaluate the performance of the obtained AR coatings, the reflectance spectra were measured using a Cary-5G spectrophotometer covering ultraviolet-visiblenear infrared range.

\section{Deposition of fixed refraction index layers}

To calibrate the deposition process of titanium and silicon oxides mixture, precisely to be able to vary the index of the deposited layers by modifying the precursors flows, several tests were carried out. The temperature of the substrates was maintained at $100{ }^{\circ} \mathrm{C}$. The oxygen flow was constant at $6 \mathrm{sccm}$. As TIPT is much more reactive with the oxygen plasma, a small variation of the flow rate between 0.5 and $1 \mathrm{sccm}$ results in sizeable variation in the film composition. TEOS flow variation should be stronger ( 2 to $6 \mathrm{sccm}$ ) because with low flow of TEOS, TIPT dominates, and we obtain practically titanium oxide.

The $\Delta=f(\psi) \quad$ experimental curves compared with corresponding Iso-indices abacuses (Fig. 1) show clearly that we can obtain films based on silicon and titanium oxides mixtures with variable refraction indices. By choosing the adequate flows, we manage to carry out films with constant indices ranging between 2.25 and 1.46 (at $500 \mathrm{~nm}$ ).
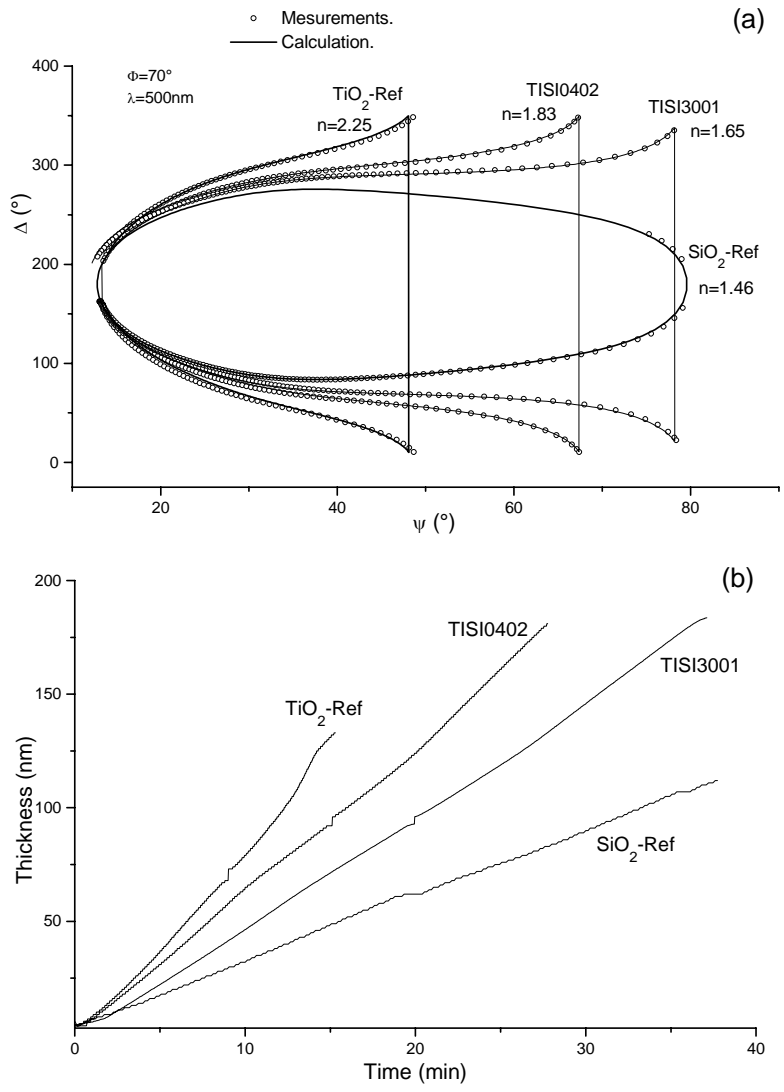

Fig. 1. In situ ellipsometry: deposition trajectories (a) and growth kinetics (b) of silicon and titanium oxides mixtures obtained by ECR-PECVD. 


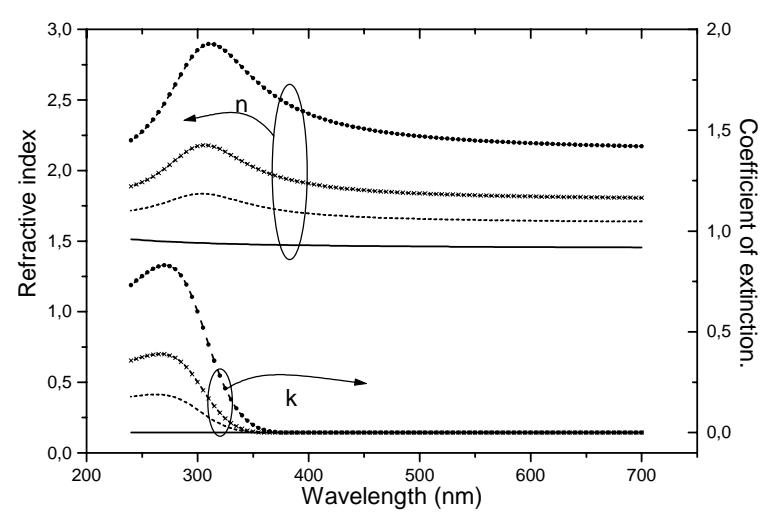

Fig. 2. Optical indices of silicon and titanium oxides mixtures.

We notice a good agreement between iso-index abacuses and experimental measurements, which form closed loops what indicates that the deposited films carried out with constant flows are homogeneous indepth. Deposition kinetics presents linear variations with higher rates for films richer in titanium oxide. Stronger indices correspond to films with high composition of titanium oxide.

The dispersion laws $n(\lambda)$ and $k(\lambda)$ of the refraction index and the extinction coefficient, respectively, represented in Fig. 2, were obtained from ellipsometric spectra measured in the range of 240 to $700 \mathrm{~nm}$. For the samples $\mathrm{TiO}_{2}$-Ref, TISI0402 and TISI3001, the ForouhiBloomer model (FBM) [17-19] gives very good results. The minimal error $\chi$ varies between $5 \cdot 10^{-4}$ and $5 \cdot 10^{-3}$. For the sample $\mathrm{SiO}_{2}$-Ref, the measured optical indices are similar to those of thermal silica [16].

Table gathers the main part of the ellipsometric investigation results carried out using the presented samples.

The Bruggeman effective medium approximation (BEMA) [20-21] is more commonly used to determine the inhomogenous film optical indices $[5,8,11]$. Using this model, we consider the deposited films as an isotropic physical mixture of two phases: silica $\mathrm{SiO}_{2}$ and titanium dioxide $\mathrm{TiO}_{2}$, homogeneous at the wavelength scale. Even if that is not completely true, this approximation gives good results in the visible and near infrared ranges $[14,22]$. Using the optical indices of $\mathrm{SiO}_{2}$-Ref and $\mathrm{TiO}_{2}$-Ref, previously determined by spectroscopic ellipsometry, the dispersion functions $n(\lambda)$ and $k(\lambda)$ of all the films consisting of $\mathrm{TiO}_{2}-\mathrm{SiO}_{2}$ mixtures can be determined by the relation:

$f_{\mathrm{SiO}_{2}} \frac{n_{\mathrm{SiO}_{2}}^{2}-\tilde{n}^{2}}{n_{\mathrm{SiO}_{2}}^{2}+2 \tilde{n}^{2}}+f_{\mathrm{TiO}_{2}} \frac{n_{\mathrm{TiO}_{2}}^{2}-\tilde{n}^{2}}{n_{\mathrm{TiO}_{2}}^{2}+2 \tilde{n}^{2}}=0$,

$f_{\mathrm{SiO}_{2}}$ and $f_{\mathrm{TiO}_{2}}$ represent the bulk fractions of $\mathrm{SiO}_{2}$ and $\mathrm{TiO}_{2}$ in the film, respectively.

\section{Graded refraction index AR coatings}

The first stage of the design proceeds by simulating the optical behavior of graded coatings to be able to optimize their performance before the stage of technological realization. It is essential to choose the appropriate profile to get minimum reflectance. The quintic (fifth-order polynomial) profile is known to drastically reduce reflection losses [23]. In this work, we suggest a profile, similar to the quintic one, which proved its effectiveness [24]. The graded refraction index can be described, using in BEMA, a bulk fraction of $\mathrm{TiO}_{2}$ variable versus depth. The profile suggested (Fig. 3) is described by the relation:

$$
f_{\mathrm{TiO}_{2}}=1-\left[1+\exp \beta\left(x-x_{0}\right)\right]^{-1} \text {. }
$$

In this expression, when the value of $\beta$ is sufficiently great, the profile becomes abrupt, and we find the configuration of a classical $\mathrm{SiO}_{2} / \mathrm{TiO}_{2}$ DLAR coating with a thickness $x_{0}$ of silica. Note that the refraction index decreases with the proportion of $\mathrm{TiO}_{2}$ from the substrate towards ambient.

The spectral reflectivity $R(\lambda)$ will be calculated using the characteristic matrix method (stratified media theory) $[1,25]$ considering the graded film as a superposition of fixed refraction index sub-layers with the same thickness $[11,14,24]$.

To optimize the AR coating performances, the spectral aspect of sunlight and the internal spectral response of solar cells must be taken into account. J. Zhao \& M.A. Green [1] consider that the photogenerated current is the best criterion to appreciate the quality of an AR coating. Indeed, the direct consequence of the reduction in reflection losses is an increase in photonic absorption, which generates more current in the

Table. Ellipsometric results.

\begin{tabular}{|c|c|c|c|c|c|c|c|c|c|c|}
\hline \multirow[b]{2}{*}{ Samples } & \multirow{2}{*}{$\begin{array}{l}\text { TIPT } \\
(\mathrm{sccm})\end{array}$} & \multirow{2}{*}{$\begin{array}{c}\text { TEOS } \\
(\mathrm{sccm})\end{array}$} & \multirow{3}{*}{$\begin{array}{l}\text { Growth } \\
\text { rate. } \\
(\mathrm{nm} / \mathrm{min}) \\
8.61\end{array}$} & \multirow{3}{*}{$\begin{array}{l}\text { Refraction } \\
\text { index } \\
\text { at } 500 \mathrm{~nm} \\
2.25\end{array}$} & \multicolumn{5}{|c|}{ Forouhi-Bloomer Model (FBM) } & \multirow[b]{2}{*}{$\chi$} \\
\hline & & & & & A & B & $\mathrm{C}$ & $n(\infty)$ & $E_{g}(\mathrm{eV})$ & \\
\hline $\mathrm{TiO}_{2}$ - Ref. & 1 & 0 & & & 0.35 & 8.12 & 0.38 & 2.05 & 3.40 & $7.810^{-4}$ \\
\hline TISI0402 & 0.5 & 2 & 6.39 & 1.83 & 0.21 & 8.03 & 0.35 & 1.80 & 3.46 & $810^{-4}$ \\
\hline TISI3001 & 0.4 & 5 & 4.95 & 1.65 & 0.12 & 8.06 & 0.59 & 1.63 & 3.37 & $310^{-3}$ \\
\hline $\mathrm{SiO}_{2}$ - Ref. & 0 & 2.5 & 2.88 & 1.46 & - & - & - & - & - & - \\
\hline
\end{tabular}




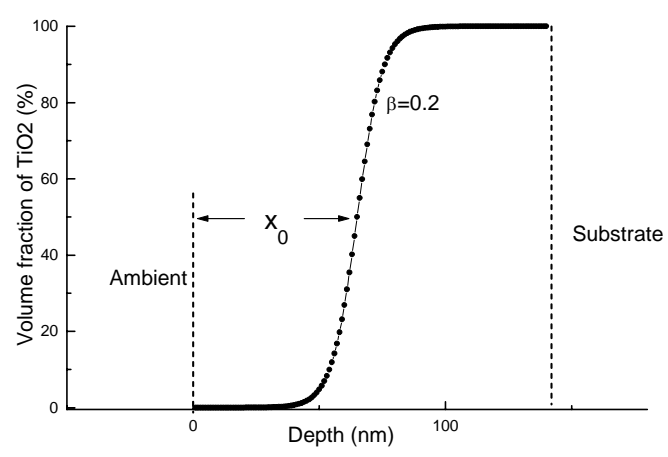

Fig. 3. Optical indices determined from ellipsometric spectra by the BEMA and FBM.

cell. This current that is approximately equal to the short-circuit current can be calculated from the spectral irradiance of the sunlight $\Phi(\lambda)$ and the internal spectral sensitivity $S(\lambda)$ of the treated cell [25-26]. The density of this current is expressed by the relation:

$J_{S C}=\int_{\lambda_{1}}^{\lambda_{2}}[1-R(\lambda)] \Phi(\lambda) S(\lambda) d \lambda$.

In this work, we used the standard spectrum AM1.5 for $\Phi(\lambda)$ and the values of $S(\lambda)$ published by M. Orgeret for a c-Si solar cell [27]. The integration covers the field of sensitivity of a silicon cell between 300 and $1100 \mathrm{~nm}$. The best improvement in $J_{S C}(50$ to $60 \%$ ) reported in literature are mainly assigned to the reduction in reflection losses. The reduction of the recombination rate at the surface by passivation of surface decreases partially contributions to this improvement, as it was evoked by certain authors [28-30]. In our case, only the losses by reflection are considered.

The gain in photocurrent due to the antireflection treatment is given by the relation:

$G_{p}=\frac{\Delta J_{S C}}{J_{S C}}=\frac{J_{S C}(\text { with RAR })-J_{S C}(\text { without RAR })}{J_{S C}(\text { without RAR })}$.

The weighted average reflectivity $R_{w}$ is also a good quality criterion for AR coatings [1,24]. It is defined within the wavelength interval $\left[\lambda_{1}, \lambda_{2}\right]$ by the relation:

$R_{W}=\frac{\int_{\lambda_{1}}^{\lambda_{2}} R(\lambda) \Phi(\lambda) S(\lambda) d \lambda}{\int_{\lambda_{1}}^{\lambda_{2}} \Phi(\lambda) S(\lambda) d \lambda}$.

Therefore, the aim becomes to determine the thickness and the index profile what permits to obtain the highest gain in photocurrent $G_{p}$ corresponding to a minimal weighted reflectivity $R_{w}$. Fig. 4 a shows the peak of the gain in photocurrent $G_{p}(\max )=48.3 \%$ for the thickness $E_{p}=145 \mathrm{~nm}$ and $x_{0}=61 \mathrm{~nm}$. In addition, the profile must be sufficiently abrupt $(\beta>0.2)$ to get high antireflection performances (Fig. 4b). The minimal average weighted reflectivity calculated within the wavelength range (300-1100 nm) was $3.57 \%$.

The theoretical curve $\Delta(\psi)$ obtained using the parameters describing the optimal refraction index profile will be used as reference mark during deposition.

\section{Graded AR coating deposition}

For graded films manufacturing, similar conditions to that described in paragraph 2 were adopted. The temperature of the sample was maintained at $100^{\circ} \mathrm{C}$ during the deposition. The pressure in the deposition chamber is close 1 mTorr. The TEOS is introduced with weak flow $(0.5 \mathrm{sccm})$ at the same time as TIPT $(2.5 \mathrm{sccm})$ before activating the oxygen plasma $\left(\mathrm{O}_{2}\right.$ flow fixed at $6 \mathrm{sccm}$ ). The TIPT reacts much more quickly than TEOS with oxygen, so under these conditions we practically obtain titanium oxide. The refraction index (at $500 \mathrm{~nm}$ ) was close to 2.2 at the beginning of the process.
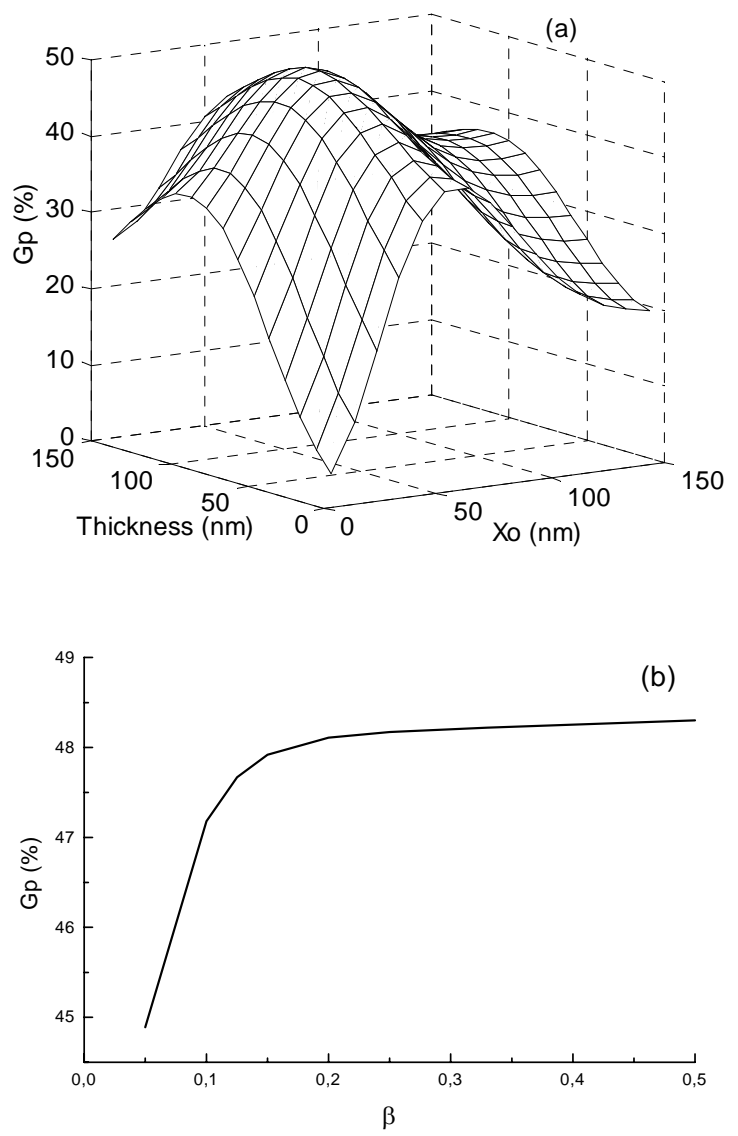

Fig. 4. AR coating suggested profile. 

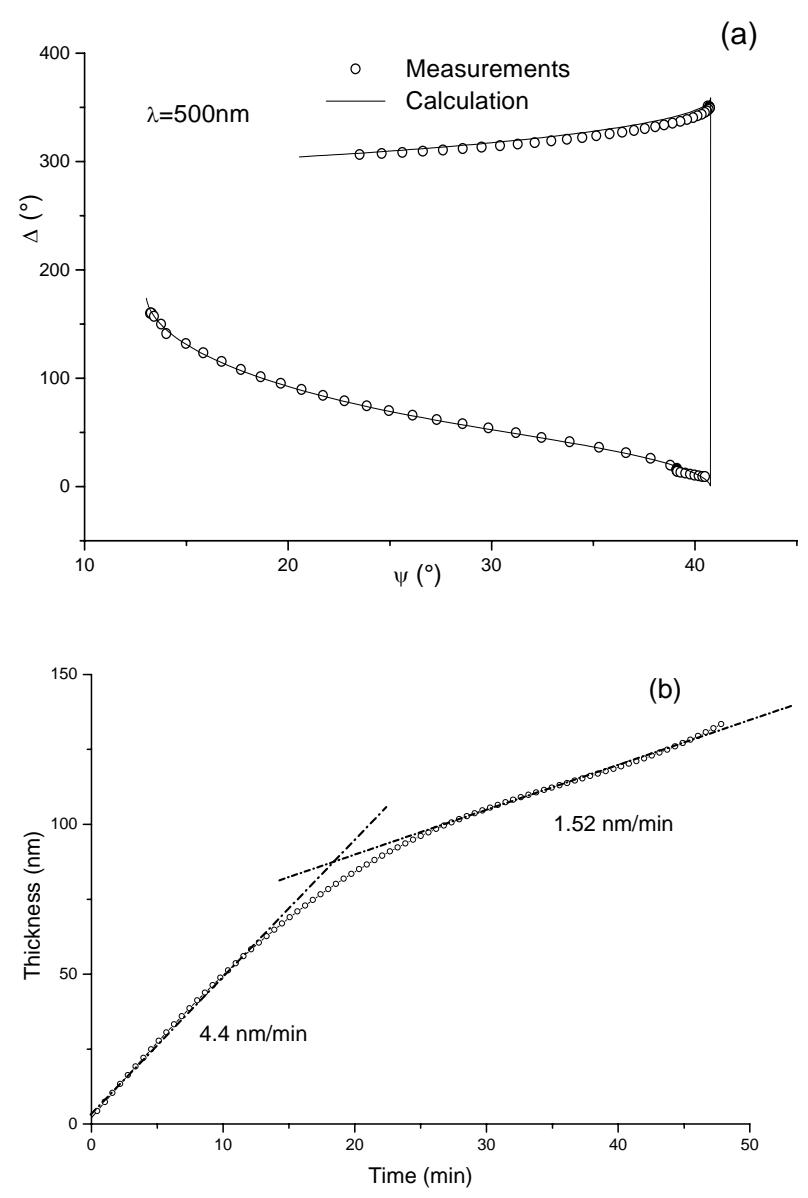

Fig. 5. Optimization of the graded AR coating performance.

During the deposition, the TEOS flow was gradually increased whereas the TIPT flow was decreased until total stop of the contribution in TIPT around a thickness of $50 \mathrm{~nm}$. At the end of the deposition, only TEOS is introduced in the reactor with a flow of $6 \mathrm{sccm}$. The latter deposited single layers are, therefore, exclusively made of silica. Fig. 5a shows the theoretical $\Delta(\psi)$ curve calculated from the profile of Fig. 3 adjusted to the experimental trajectory.

Deposition kinetics (Fig. 5b) clearly shows a reduction of the growth ratios between the beginning of the deposition (titanium oxide) and the end (silicon oxides).

An ellipsometric spectrum was taken after deposition to determine the index profile carried out and the thickness of the deposited layer. The adjustment of the theoretical curves to the experimental spectra by minimizing the error function $\chi$ permits to determine the thickness and the parameters $x_{0}$ and $\beta$, which define the obtained index profile.

Fig. 6 shows a good agreement between the theoretical and experimental spectra. The function of error is about $2 \cdot 10^{-3}$. The deposited thickness of $150 \mathrm{~nm}$ is slightly higher than the optimal value given in the

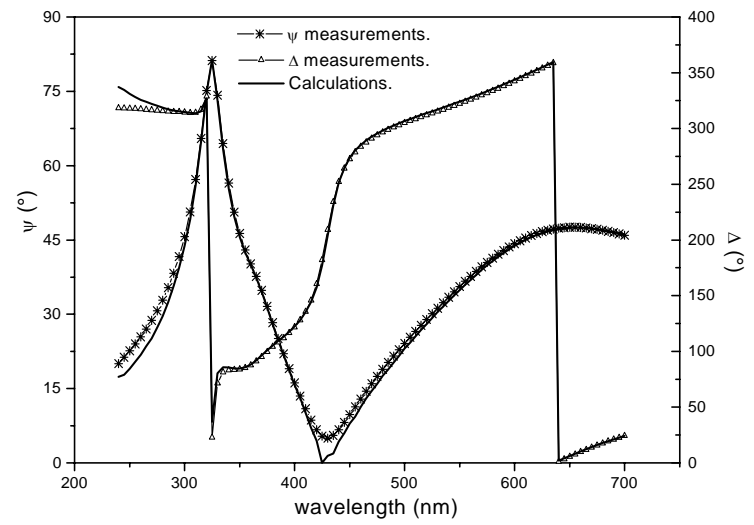

Fig. 6. In situ ellipsometric control of the graded coating deposition (a), growth kinetics of graded film (b).

proceeding paragraph. To define the form of the profile, the minimization results give $x_{0}=58 \mathrm{~nm}$ and $\beta=0.26$.

The reflectivity was measured between 300 and $1100 \mathrm{~nm}$ and was compared with that of bare silicon. Fig. 7 shows the significant reduction due to the presence of graded index AR coating: the average weighted reflectivity $R_{w}$ decreases from $35 \%$ for bare silicon to $3.7 \%$ after deposition of the graded index AR coating. The short-circuit current could then be improved of $48 \%$. In recent work, B.S. Richards \& $\mathrm{Al}$ [31] obtained the average weighted reflectivity of $6.5 \%$ by using double-layers AR coating using porous $\mathrm{TiO}_{2}$ deposited by atmospheric pressure chemical vapour deposition (APCVD). K.L. Jiao \& $\mathrm{Al}$ have reported photocurrent gains between 40 and $46 \%$ using $\mathrm{TiO}_{2} / \mathrm{SiO}_{2}$ classical DLAR coating [6]. The result obtained using the suggested graded coating is therefore very satisfying, especially if we know that ideal $G_{p}$ gain that we could obtain by complete elimination of reflection losses should be approximately equal to $53 \%[26]$.

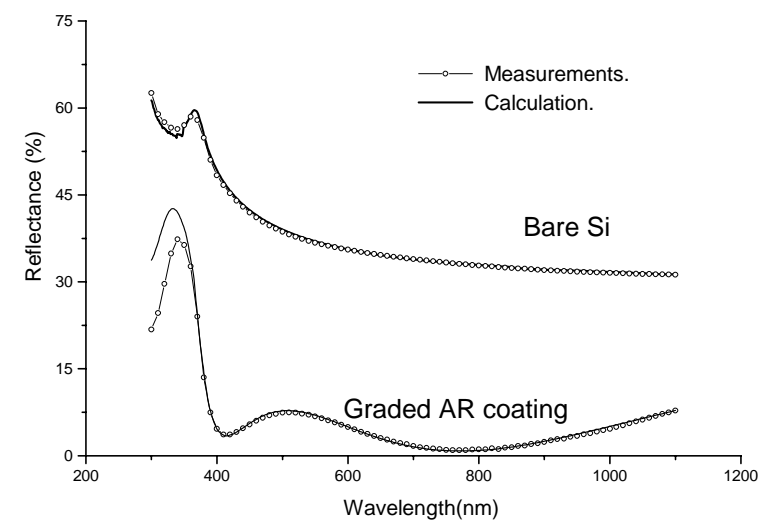

Fig. 7. Ellipsometric spectra of the graded AR coating. 


\section{Conclusion}

Inhomogeneous dielectric films can be deposited at low temperature by ECR-PECVD using two precursors (TIPT and TEOS). The obtained films consisting of silicon and titanium oxides are chemically stable and practically transparent over all the solar spectrum. Therefore, they are particularly interesting for the realization of antireflection coatings. Graded AR coatings, fabricated in only one technological stage, permits to avoid the problems of interfaces met in the fabrication of classical multilayer AR coatings. The in situ ellipsometry control of thickness and refraction index makes it possible to optimize the performances of these coatings. The measured weighted average reflectivity around 3.7 and $48 \%$ enhancement of photocurrent were obtained. These values very close to the calculated optimal performances confirm the effectiveness of the deposition control by in situ ellipsometry.

\section{Acknowledgements}

We would like to thank the research group of Professor J. Joseph of ECLyon, especially A.S. Callard and A. Gagnaire, for their assistance in accomplishing this work. We also would like to thank R. Dubend and B. Devif for technical support.

\section{References}

1. J. Zhao and M.A. Green, Optimized antireflection coatings for high-efficiency solar cells // IEEE Trans. Electron Devices 38(8) p. 1925-1934 (1991).

2. D.H. Macdonald, A. Cuevas, M.J. Kerr, C. Samundsett, D. Ruby, S. Winderbaum, A. Leo, Texturing industrial multicrystalline silicon solar cells // Solar Energy 76, p. 277-283 (2004).

3. A.G. Arbele, Overview on SiN surface passivation of crystalline silicon solar cells // Solar Energy Materials \& Solar Cells 65, p. 239-248 (2001).

4. A. Hauser, M. Spiegel, P. Fath and E. Bucher, Influence of an ammonia activation prior to the PECVD SiN deposition on the solar cell performance // Ibid. 75, p. 357-362 (2003).

5. C. Martinet, V. Paillard, A. Gagnaire, J. Joseph, Deposition of $\mathrm{SiO}_{2}$ and $\mathrm{TiO}_{2}$ thin films by plasma enhanced chemical vapor deposition for antireflection coating // J. Non-crystalline Solids 216, p. 77-82 (1997).

6. K.L. Jiao, W.A. Anderson, $\mathrm{SiO}_{2} / \mathrm{TiO}_{2}$ double-layer antireflective coating deposited at room temperature for metal/insulator / $\mathrm{n}-\mathrm{Si} / \mathrm{p}$-Si solar cells // Solar Cells 22, p. 229-236 (1987).

7. G.A. Neuman, Antireflective coatings by APCVD using graded index layers // J. Non-crystalline Solids 218, p. 92-99 (1997).

8. M. Farooq and M.G. Hutchins, A novel design in composities of various materials for solar selective coatings // Solar Energy Materials \& Solar Cells 71(4), p. 523-535 (2002).

9. M.F. Ouellette, R.V. Lang, K.L Yan, R.W. Bertram, R.S. Owles, D. Vincent, Experimental studies of inhomogeneous coatings for optical applications // J. Vac. Sci. Technol. A 9(3), p. 1188-1192 (1991).

10. X. Wang, H. Masumoto, Y. Semeno, T. Hirai, Microstructure and optical properties of amorphous $\mathrm{TiO}_{2}-\mathrm{SiO}_{2}$ composite films synthesized by helicon plasma sputtering // Thin Solid Films 338, p. 105109 (1999).

11. S. Callard, A. Gagnaire, J. Joseph, Fabrication and characterisation of graded refraction index silicon oxynitride thin films // J. Vac. Sci. Technol. A 15(4), p. 2088-2094 (1997).

12. C. Robert, L. Bideux, B. Gruzza, T. Lohner, M. Fried, A. Barna, K. Somogyi, and G. Gergely, Ellipsometry of $\mathrm{Al}_{2} \mathrm{O}_{3}$ thin films deposited on $\mathrm{Si}$ and InP // Semicond. Sci. Technol. 12, p. 14291432 (1997).

13. R.M. Azzam and N.M. Bashara, Ellipsometry and polarized light. North Holland, Amsterdam, 1977.

14. S. Callard, A. Gagnaire, J. Joseph, Characterisation of graded refraction index silicon oxynitride thin films by spectroscopic ellipsometry // Thin Solid Films 313-314, p. 384-388 (1998).

15. D.E. Apnes and J.B. Theeten, Dielectric function of $\mathrm{Si}_{-} \mathrm{SiO}_{2}$ and $\mathrm{Si}_{3} \mathrm{~N}_{4}$ mixtures // J. Appl. Phys. 50, p. 4928-4935 (1979).

16. E.D. Palik, Handbook of optical constant of solids. Academic Press Handbook Series, Orlando, 1985.

17. A.R. Forouhi and I. Bloomer, Optical dispersion relations for amorphous semiconductors and amorphous dielectrics // Phys. Rev. B 34, p. 70187023 (1986).

18. B. Masenelli, A. Gagnaire, L. Berthelot, J. Tardy and J. Joseph, Controlled spontaneous emission of a tri(8-hydroxyquinoline) aluminium layer in a microcavity // J. Appl. Phys. 85(6), p. 3032-3037 (1999).

19. E.D. Palik, Handbook of optical constant of solids II. Academic Press, 1991, p. 151-175.

20. M. Born and E. Wolf, Principles of optics. Pergamon Press, 1970.

21. L. Gao and J.Z. Gu, Effective dielectric constant of a two-component material with shape distribution // J. Phys. D: Appl. Phys. 35, p. 267-271 (2002).

22. J. Rivory, Characterization of inhomogeneous dielectric films by spectroscopic ellipsometry // Thin Solid Films 313-314, p. 333-340 (1998).

23. W.H. Southwell, Gradient-index antireflection coatings // Opt. Lett. 8(11), p. 584 (1983).

24. Mahdjoub and L. Zighed, New designs for graded refraction index antireflection coatings // Thin Solid Films 478, p. 299-304 (2005).

25. P. Nubile, Analytical design for antireflection coatings for silicon photovoltaic devices // Thin Solid Films 342, p. 257-261 (1999). 
26. D.J. Aiken, High performance anti-reflection coatings for broadband multi-junction solar cells // Solar Energy Materials \& Solar Cells 64, p. 393404 (2000).

27. Mr. Orgeret, Solar cells: The component and its applications. Masson Editions, 1985.

28. Z. Chen, P. Sana, J. Salami, A. Rohatgi, A novel and effective PECVD $\mathrm{SiO}_{2} / \mathrm{SiN}$ antireflection coating for Si sollar cells // IEEE Trans. Electron. Devices 40(6), p. 1161-1165 (1993).

29. F. Duerinckx and J. Szlufcik, Defect passivation of industrial multicrystalline solar cells based on
PECVD silicon nitride // Solar Energy Materials \& Solar Cells 72, p. 231-2146 (2002).

30. J. Schmidt, M. Kerr and A. Cuevas, Surface passivation of silicon solar cells using plasmaenhanced chemical-vapour-deposited SiN films and thin thermal $\mathrm{SiO}_{2} /$ plasma $\mathrm{SiN}$ stacks // Semicond. Sci. Technol. 16, p. 164-170 (2001).

31. B.S. Richards, S.F. Rowlands, C.B. Honsberg and J.E. Cotter, $\mathrm{TiO}_{2}$ DLAR coatings for planar silicon solar cells // Progr. Photovolt.: Res. Appl. 11, p. 27-33 (2003). 